\title{
Planned Treatment Regimen
}

National Cancer Institute

\section{Source}

National Cancer Institute. Planned Treatment Regimen. NCI Thesaurus. Code C103161.

The intended treatment plan that specifies the dosage, the schedule, and the duration of treatment. 